\title{
Is there life after degeneration? The organizational life cycle of cooperatives under a 'grow-or-die' dichotomy
}

\author{
Ignacio Bretos ${ }^{1, *}$ (1) | Anjel Errasti ${ }^{2, *} \quad$ | Carmen Marcuello ${ }^{3, *}$
}

\footnotetext{
${ }^{1}$ University of Zaragoza, Spain

${ }^{2}$ University of the Basque Country, Spain

${ }^{3}$ University of Zaragoza, Spain
}

ibretos@unizar.es, a.errasti@ehu.eus, cmarcue@unizar.es

* The authors gratefully acknowledge financial support from the Regional Government of Aragon and the European Regional Development Fund [Construyendo Europa desde Aragón], as well as from the Research Group 'Gizarte Ekonomia eta bere Zuzenbidea' [GIU17/052], attached to the GEZKI Institute of Cooperative Law and Social Economy, University of the Basque Country (UPV/EHU).E-mails: ibretos@unizar.es; a.errasti@ehu.eus; cmarcue@unizar.es

\section{Funding information}

Regional Government of Aragon; European Regional Development Fund, Grant/Award Number: GIU17/052; Euskal Herriko Unibertsitatea, Grant/Award Number: UPV/EHU

\begin{abstract}
This article provides an in-depth, longitudinal analysis combining real-time and retrospective data on a set of Mondragon's industrial cooperatives that are organized as international groups. We examine the life cycle of these international cooperative groups, which is expected to evolve differently to that of small- and medium-sized cooperatives that operate exclusively on a local scale. The article is theoretically informed by the cooperative life cycle theory, as well as by recent insights from the degeneration and regeneration theses. Our analysis yields an intricate picture of the evolution of cooperatives faced with a 'grow-or-die' dichotomy. On the one hand, our findings reject the highly simplistic and deterministic view of the degeneration thesis by demonstrating that these cooperatives can mobilize resources to revitalize cooperative values and practices. On the other, we find that regeneration may not occur in a consistent, sequential fashion as the previous literature suggests, but rather degenerative and regenerative tendencies can occur simultaneously, even leading to long-lasting, unresolvable situations. In light of this, the article asks future research to draw on power-aware and politically informed approaches for further understanding of how cooperatives manage the tensions at each organizational stage of their life cycle, and of which
\end{abstract}


organizational actors benefit, and how, from reversing some degenerative tendencies while maintaining others intact.

\section{KEYWORDS}

Cooperatives, Degeneration, Governance, Organizational life cycle, Mondragon, Regeneration

JEL CLASSIFICATION :

F23, J54, M16

\section{1 | INTRODUCTION}

The last decade has witnessed a resurgence of interest in the internal changes and organizational trajectories experienced by member-based organizations; that is, 'organizations that on principle rely on the equal status and democratic participation of their members to reach their goals' (Jaumier 2017, p. 218). As noted by Rothschild (2016), collectivist-democratic forms of organization, which include, among others, self-help groups, micro-credit groups, cooperatives, and social movement organizations, have proliferated over recent years, posing a growing alternative to hierarchical and bureaucratic forms of organization. In this context, some recent studies have challenged the orthodox view of Michels's iron law of oligarchy which asserts that '[o]rganization implies the tendency to oligarchy' (Michels 1915: 26), both by revisiting the concept of oligarchy in the light of different democratic and oligarchic distributions of power across organizational forms (Leach 2005, Diefenbach 2018), and by illustrating how various forms of democratically structured organizations can resist oligarchization (Martin 2015).

In particular, cooperatives have attracted prominent attention, with several authors bringing back longstanding debates on degeneration and regeneration. According to Storey et al. (2014), analysis of cooperatives in a capitalist setting has been traditionally dominated by the degeneration thesis, which holds that cooperatives must adopt the same forms and priorities as capitalist firms if they are to survive in the market, and as a result will gradually become dominated by an oligarchy (Cornforth 1995: 488). Thus cooperatives are expected to follow a life cycle that concludes with either commercial failure or their progressive degeneration and eventual transformation into capitalist firms (Webb and Webb 1921, Meister 1984). This perspective still shows signs of hegemony. Various studies suggest that growing economic requirements and managerialism trends associated with a competitive market economy and a neoliberal ideology have permeated many cooperatives, imposing unavoidable pressures towards degeneration (e.g. Cathcart 2013; Paranque and Willmott 2014).

Other authors have focused on the processes and conditions that lead cooperatives to retain their egalitarian democratic functioning over time and avoid degeneration, highlighting their ability to balance the conflicting logics and aims of market-embedded demand for organizational efficiency on the one hand, and culturally-embedded values for inclusive engagement and democracy on the other (Varman and Chakrabarti 2004, Hernandez 2006, Langmead 2016, Jaumier 2017). In addition, a smaller but growing line of research has highlighted cooperatives' potential to regenerate; that is, to revive cooperative values and re-assemble democratically-structured forms

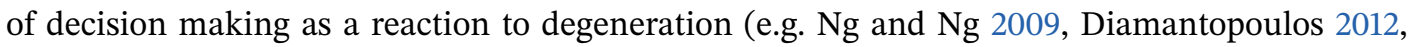


Giagnocavo et al. 2014, Storey et al. 2014, Narvaiza et al. 2017). These studies illustrate how cooperatives can regenerate by mobilizing resources to trigger organizational change, such as by reinforcing a culture of discussion and open criticism and strengthening members' active participation.

While this literature provides essential contributions, we still lack comprehensive understanding of the various degenerative and regenerative tendencies that occur within cooperatives and other member-based organizations (Jaumier 2017, Narvaiza et al. 2017). Indeed, as Diefenbach (2018: 15) recently claimed, '[h]ow, and especially why, some of these organizations work and are successful in keeping their character as democratic organizations over many years is somewhat underexplored and under-researched'. In this article, we provide a longitudinal study of a set of Mondragon's industrial cooperatives that have struggled for decades to develop successfully in international markets while utilizing democratic methods. The relevance of this analysis is supported by the fact that globalization pressures have confronted many cooperatives with a 'grow-or-die' dichotomy: if they are to survive in increasingly globalized markets, they must internationalize in order to maintain their competitiveness (Bretos and Marcuello 2017). Indeed, mounting empirical research has documented the internationalization of cooperatives (e.g. Bretos et al. 2018a). While international growth is a prerequisite for many cooperatives to remain competitive, on the other hand this process might compromise their long-held values and institutionalized practices (Flecha and Ngai 2014, Bretos et al. 2018b).

More specifically, we contribute to advancing understanding of the cooperative life cycle in two main ways. Firstly, while the previous literature has generally examined degenerative and regenerative tendencies in small- and medium-sized cooperatives that operate exclusively at a domestic level, our article examines these processes in large cooperatives competing on a global scale and controlling a range of subsidiaries. Secondly, unlike the previous literature, which tends to depict regeneration as a consistent and homogeneous process that permeates the organizational structures and dynamics of the cooperative, we show that regeneration can take place in a partial fashion; that is, with some organizational dynamics and practices reverting while others remain intact.

The paper is organized as follows: the next section lays its theoretical foundations by briefly reviewing the cooperative life cycle theory; the third section details the research methods and the data; the fourth discusses the main results of our research, and the final section provides some concluding remarks.

\section{2 | THE COOPERATIVE LIFE CYCLE THEORY}

The emergence of neo-institutionalism in the late 1970s was an important milestone in understanding the existing homogeneity of organizational forms and practices, that is, why organizations tend to resemble one another (e.g., Meyer and Rowan 1977, DiMaggio \& Powell 1983). According to neo-institutional theory, organizations tend to 'become isomorphic with their institutional context in order to signal their social fitness and gain legitimacy in the eyes of critical constituencies' (Greenwood et al. 2008: 4). It is argued that this process is driven by three types of isomorphic pressures: (1) coercive isomorphism that stems from political influence and the problem of legitimacy; (2) mimetic isomorphism resulting from standard responses to uncertainty; and (3) normative isomorphism, associated with professionalization (DiMaggio and Powell 1983).

The question of isomorphism in cooperatives has aroused controversial debate since the end of the nineteenth century. When studying the evolution of British cooperative societies, the Webbs observed a reduced degree of survival among these enterprises and concluded that 


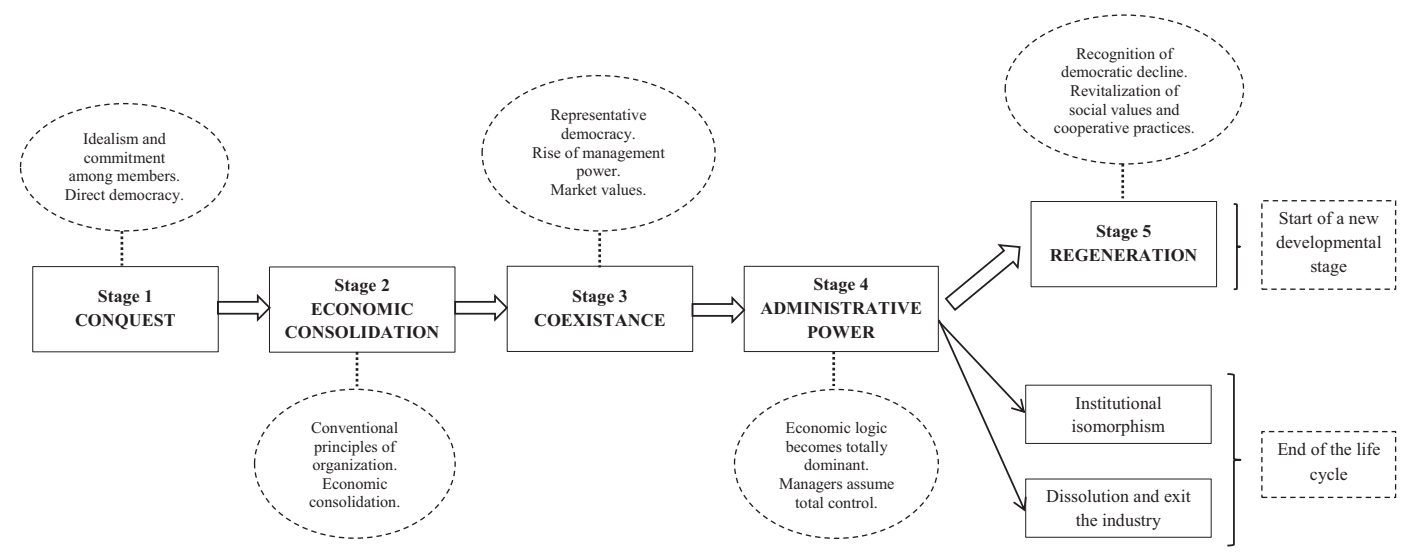

F I G U R E 1 Stages of the cooperative life cycle.

Source: Own elaboration.

the few organizations that had managed to survive had quickly collapsed as 'democracies of producers' and turned into 'associations of capitalists' (Webb and Webb 1921). The Webbs' statement inaugurated the well-known 'degeneration thesis', which experienced notable development, fundamentally during the 1970s and 1980s (see, among others, Ben-ner 1984, Meister 1984, Miyazaki 1984, Russell 1984). Following the landmark study by Cornforth et al. (1988), three main degenerative dynamics can be distinguished in cooperatives. Firstly, constitutional degeneration involves cooperatives adopting capitalist forms of organization in which employees are excluded from the rights and benefits of cooperative membership. Secondly, organizational degeneration implies that employee involvement in decision making is diminished in favor of control by a managerial elite or technocracy. Thirdly, goal or cultural degeneration entails the prevalence of the conventional business goals of profit seeking and growth over socially-oriented targets.

According to the degeneration literature, cooperatives and other democratic organizations tend to experience a life cycle, marked by the deterioration of their participatory structures and the growing heterogeneity in members' preferences. Four major stages have been distinguished to depict how degeneration evolves in a sequential fashion: conquest, economic consolidation, coexistence, and administrative power (Meister 1984, Rosner 1984, Cornforth 1995, Chaves and Sajardo 2004, Cook 2018). This gradual process would eventually result either in the dissolution of the cooperative or in a process of isomorphism with the dominant institutional environment (see Figure ).

In the first stage, conquest, the cooperative has just been created, usually by a small group of members who join to meet their common economic, social, and cultural goals through a jointlyowned organization. Members' idealism and commitment are high, and democracy is essentially practised on a direct basis, with decisions being made in the assembly and the notable involvement of all members of the organization. The governing bodies are not yet well defined, and the cooperative's economic activity and functions are poorly established (Meister 1984, Rosner 1984). The second stage, economic consolidation, comprises a period of transition during which, if the cooperative survives, conventional principles of organization are adopted and further economic consolidation is achieved. Initial idealism is overshadowed by indifference and apathy and the power of management is strengthened, giving rise to growing conflict between idealists 
and practical-minded managers (Meister 1984, Cornforth 1995). In the third stage, coexistence, symptoms of degeneration become apparent. Market values permeate the cooperative and are accepted by the members at the expense of radical ideals and social goals. Direct democracy is diluted and decision-making power becomes restricted to a representative board, giving rise to a greater gap between managers and other members as growth and efficiency concerns are addressed with greater division of labor and role specialization. Economic activity, decisions and information for members become increasingly complex. While the size of the organization usually increases, in contrast the members' criticism and control decrease, and social activities are abandoned or become marginal (Rosner 1984, Cornforth 1995). During the fourth stage, of administrative power, economic logics dominate and members and their representatives lose their power as control is completely assumed by the managers (Chaves and Sajardo 2004, Meister 1984).

The degeneration literature contends that this four-stage process may eventually result in one of the following two options: (i) the cooperative is dissolved and exits the industry as the organization no longer serves to achieve the members' initial objectives; or (ii) the cooperative experiences isomorphism, either by morphing into some other organizational form, usually as an investorowned firm better-suited to the interests and preferences of the management and other members, or by falling into a state of inaction in which the business is run healthily but social values and ideals are dormant (Cornforth et al. 1988, Cook 2018).

This four-stage framework, however, has been criticized by a number of authors who suggest that cooperatives are able to maintain their original nature in the long term, and that degeneration may be a temporary stage followed by the setup of regeneration processes with the power to restore their democratic, participative social functioning (Batstone 1983, Rosner 1984, Hunt 1992, Cornforth 1995). This body of research, labeled the 'regeneration thesis', claims that the life cycle of cooperatives does not conclude with degeneration but may lead to a fifth developmental stage, regeneration, in which democracy is reinvented. This stage basically involves recognition and repositioning. Members collectively recognize a decline in the quality of democratic practice within the organization and trigger various processes to reaffirm the initial values and ideals, reconstitute social goals, and reignite cooperative practices. This stage does not usually involve a total return to the direct democracy initially practised but rather takes the form of more conventional forms of worker representation, reflecting the increase in the organizational size of the cooperative and the organizational changes described above. However, the management power of the technostructure is clearly curbed, and the interests of labor are reinforced at the expense of those of capital.

In the last few years renewed debate has emerged about the life cycle of cooperatives. Some studies have focused on the growing degenerative tendencies of cooperatives seeking to survive in a global market economy. These include the technocratization of management (Chaves and Sajardo 2004), the emergence of oligarchic trends that displace democracy and grassroots participation (Heras 2014, Paranque and Willmott 2014), the embracement of market values and corporate discourses that privilege managerial interests (Cathcart 2013, 2014, Heras and Basterretxea 2016), and the transformation of cooperatives into investor-owned firms (Sousa and Herman 2012). Some authors also illustrate how severe competitive pressures and adverse economic conditions may lead cooperatives to cease operations altogether and exit the industry (Errasti et al. 2017). Other studies, meanwhile, have demonstrated that cooperatives and other member-based organizations can resist degeneration and achieve a healthy balance between oligarchy and democracy by both maintaining their original nature in the long term 
and revitalizing their democratic functioning over time ( $\mathrm{Ng}$ and $\mathrm{Ng} \mathrm{2009,} \mathrm{Storey} \mathrm{et} \mathrm{al.} \mathrm{2014,}$ Narvaiza et al. 2017). A variety of mechanisms are highlighted, including the reenactment of a democratic discourse that countervails the dominant market rhetoric (Eikenberry 2009); the reproduction of an active membership through careful selection of managers and workers and their socialization into cooperative values (Chaves and Sajardo 2004); the permanent requirement for accountability and endless overt critique of managers to circumvent the coalescence of power in their hands (Jaumier 2017); the organization of labor to reinforce a participatory culture grounded in self-determination, horizontality and solidarity (Hernandez 2006); connection to wider social movements to promote community-based goals (Diamantopoulos 2012, Langmead 2016), and the eventual 'remutualization' of cooperatives (Sousa and Herman 2012).

However, we argue that two factors are critical to further advancing our understanding of the cooperative life cycle. Firstly, research to date has generally examined the evolution of smalland medium-sized cooperatives operating exclusively at a domestic level (e.g., Varman and Chakrabarti 2004, Hernandez 2006, Ng and Ng 2009, Langmead 2016, Jaumier 2017, Narvaiza et al. 2017), where degenerative and regenerative tendencies tend to occur in an informal way, largely depending on the role of individual leaders ( $\mathrm{Ng}$ and $\mathrm{Ng}$ 2009, Narvaiza et al. 2017). These tendencies are expected to evolve differently in large cooperatives operating on a global scale with a range of foreign subsidiaries. Here, international growth might impose unique degenerative pressures on formal and informal democratic structures and processes and open up a wider range of regeneration strategies (Bretos and Marcuello 2017). The few studies dealing with international cooperative groups in this field have focused on the degenerative dynamics triggered by the acquisition or setting-up of non-cooperative offshoots, and the possibilities of regeneration through the ‘cooperativization' of these capitalist firms (Flecha and Ngai 2014, Bretos and Errasti 2016, 2017). However, what is lacking is a wide-ranging analysis that takes into account the life cycle of international cooperative groups over a long time span.

Secondly, much of the early literature appears to depict regeneration as a consistent, homogeneous process that 'breathes life back into cooperative ideals' (Batstone 1983: 150), leading the cooperative to a new organizational stage in which the previous structural, cultural, and organizational dynamics of degeneration are fully overcome (e.g. Batstone 1983, Rosner 1984, Hunt 1992). Some more recent studies conceptualize cooperatives as paradoxical spaces in which members permanently struggle to find a balance between competing market and social demands (Hernandez 2006, Ng and Ng 2009, Storey et al. 2014, Narvaiza et al. 2017). This implies that cooperatives might tend to conduct processes of partial regeneration, reverting only to certain organizational dynamics and practices while others remain unaltered so that the cooperative can continue to exploit resources drawn from market logics.

\section{3 | METHODOLOGY}

\section{1 | Research approach}

To address the questions raised above we designed an in-depth, longitudinal case study (Yin 1984) informed by a 'process view', which puts the spotlight on the centrality of time by examining 'how and why things emerge, develop, grow, or terminate over time' (Langley et al. 2013: 1, see also Langley 1999). Process questions 'are fundamental for gaining an appreciation of dynamic social life, 
and developing and testing theories of "how" social entities adapt, change, and evolve over time' (Van de Ven 2007: 145), and have been widely used to shed light on complex processes of organizational change (Langley et al. 2013). This method appears especially suited to understanding why cooperatives degenerate and regenerate, and how these organizational processes evolve over time.

Our theoretic approach combines inductive theory generation and deductive theory verification (Orton 1997), a mixed approach that 'allows one to gain creative insight from the data, without necessarily denying or reinventing concepts that have been useful previously' (Denis et al. 2001: 812). We assumed that cooperative life-cycle theory could be useful to make sense of our empirical observations and at the same time, we expected our findings to enrich our knowledge about the degenerative and regenerative dynamics of cooperatives.

\section{2 | Empirical context}

The setting for our study was the Mondragon Cooperative Corporation (MCC), a network that comprises about 270 organizations and 75,000 workers worldwide in the areas of industry, education-knowledge, retail, and finance. MCC is based in the Basque Country, a region that boasts one of the most developed Social Economy sectors in Spain (Bretos and Morandeira 2016). MCC's Industrial Division consists of 68 worker cooperatives, of which about half are organized as international groups controlling a total of 140 subsidiaries in more than 20 countries. These organizations engage in very diverse economic activities including industrial automation, construction, household appliances, automotive components, machine tooling, and industrial equipment (Mondragon 2017).

The study examines in detail the cases of Fagor Ederlan, Maier Group, and Fagor Electrodomesticos. We selected these cooperatives because they offer varied insights into the life cycle of cooperatives. In 2013, Electrodomesticos, Mondragon's flagship group, declared bankruptcy after 57 years of operation. Before its collapse it employed nearly 11,000 workers at 18 plants across Spain, France, China, Poland, Morocco, and Italy (Errasti et al. 2016, 2017). Ederlan, a leading supplier to the automotive industry employing about 3,800 workers at 18 production settlements in Spain, Mexico, China, Brazil, and Slovakia, came into being in 1963 and today stands out as one of MCC's most active cooperatives in terms of the design and implementation of regeneration initiatives, including the conversion of capitalist subsidiaries into cooperatives at the domestic level (Bretos and Errasti 2016, 2017), and some efforts to introduce the cooperative model in its foreign subsidiaries (Bretos et al. 2018, 2019). Maier was founded in 1975 and specializes in the manufacturing of automobile plastic components and injection moldings. Today the company employs 3,200 workers at 10 plants in Spain, the UK, the Czech Republic, Italy, China, Mexico, and India. Maier is currently embarked on an ambitious process of international expansion and has recently opened factories in India, China, and Mexico.

\section{3 | Data sources}

Real-time and retrospective longitudinal data were collected via semi-structured interviews and from archival sources. The information gathered covers the period from the very formation of the Mondragon Cooperative Experience in the 1950s to 2018. As noted by Ozcan and Eisenhardt 
(2009), this data combination is ideal for understanding the sequence and flow of events, as retrospective data enable the efficient gathering of more observations, while real-time data mitigate any retrospective bias and allow for finer-grained tracking, improving understanding of how events evolve over time (see also Leonard-Barton 1990).

We collected a wide range of archival documents from Mondragon including historical records about its early years, annual reports, strategic plans, internal presentations and documents, corporate videos, press releases, in-house magazines, published research articles, and information from corporate websites. These documentary and archival data were particularly useful for building a context-sensitive, historically grounded case (Yin 1984) and capturing the Mondragon cooperatives' initial developmental stages.

The study also relies on 45 semi-structured interviews: 17 interviews were conducted at Electrodomesticos during 2014, with 18 at Ederlan between 2013 and early 2017, and 10 at Maier between 2015 and late 2016. The interviews were carried out at cooperative headquarters and some domestic plants and lasted 90 minutes on average. Our informants included top managers, such as an HR director and a managing director; middle-ranking managers, generally from the production and HR departments; representatives of the cooperative governing bodies; rank-and-file worker-members; and salaried and temporary employees. The interviewees were asked to report important events, actions, and behaviors in the history of their cooperative from its inception until the present. Some relevant questions addressed how they perceived the evolution of their cooperative in terms of the reshaping of its culture and values and the transformation of its governance structures and participation mechanisms. They were also asked to elucidate the reasons behind and consequences of the extensive growth that these cooperatives have pursued throughout their history, and how their corporate discourse and practices of regeneration have evolved over the last years.

\section{4 | Data analysis}

The data analysis followed common prescriptions for longitudinal case studies (Yin 1984, Langley 1999), and involved a two-step procedure. In the first stage, we reconstructed the history of Mondragon's cooperatives by organizing the case-study data into an event history database which collated the descriptions of events chronologically based on the raw interview and archival data (Karra et al. 2006). This permitted the construction of a narrative about the emergence and organizational development of Mondragon's cooperatives in various important periods of change (see Table). These periods do not necessarily represent homogeneous, static stages that take place sequentially, but should be rather understood as dynamic stages that are mutually shaped and intertwined in a multidirectional fashion, enabling 'explicit examination of how actions of one period lead to changes in the context that will affect action in the next' (Denis et al. 2001: 815).

In the second stage, we documented and tracked the critical events that had led to organizational changes in the cooperatives and how these changes were reflected in the organizational structures, processes and culture. We moved iteratively between data and theory rather than in a linear fashion, until 'theoretical saturation' was reached (Ozcan and Eisenhardt 2009). Throughout the process, triangulation of individual respondents' accounts with those of other respondents and with the archival data allowed us to mitigate informant biases and refine our emerging interpretations (Yin 1984). This produced a synthesis anchored both theoretically in the literature and empirically in our data (Karra et al. 2006). 
TA B L E 1 Critical events in the development of Mondragon's international cooperative groups

$\begin{aligned} & \text { Approximate } \\ & \text { dates/period }\end{aligned}$
$\begin{aligned} & \text { Emey events and issues } \\ & \text { 1956-1970 } \\ & \text { cooperative groups. Rapid organizational and economic consolidation. } \\ & \text { Extensive growth in the domestic market and associated tensions } \\ & \text { surrounding democratic governance and worker participation. }\end{aligned}$
Implo-1990
Impact of the Spanish economic crisis. Further organizational consolidation
through the development of new policies to withstand recession situations.
Spain enters the European Union. Arrival of multinational enterprises with
more innovative and efficient processes.
Creation of the Mondragon Cooperative Corporation holding structure to
promote cooperative activity and synergies in the fields of
internationalization, R\&D initiatives, investment, financing, training, and
so on.
Start of the international expansion of most of Mondragon's international
cooperative groups. Intensification of economic and productive
requirements. Escalation of various degenerative pressures and tensions.
Beginning of ideological discussions and internal reflections within several
large cooperatives oriented towards revitalizing the cooperative culture
and practices.
Collective recognition of the erosion of the cooperative culture and
emergence of vigorous debate about the future of the Mondragon
Cooperative Experience. Formalization of regeneration guidelines and
initiatives by both the MCC and cooperative firms.
Impact of the economic crisis. Partial abandonment of the regeneration
discourse and practices in various cooperatives to focus on economic
survival.
Bankruptcy of the household appliance manufacturer Fagor
Electrodomesticos.
Revival of the regeneration debate, but reshaped by both the MCC and its
first-tier cooperatives, particularly regarding the cooperativization of
subsidiaries.

\section{4 | RESEARCH FINDINGS: THE LIFE CYCLE OF MONDRAGON'S INTERNATIONAL COOPERATIVE GROUPS}

\subsection{Initial development and flourishing of Mondragon cooperatives (1956-1990)}

The Mondragon cooperative movement flourished more than 60 years ago in the Mondragon valley (Gipuzkoa, Basque Country) in a postwar context marked by poverty, miserable income, unemployment, and appalling working conditions (Molina and Miguez 2008). From its beginnings, Mondragon was a project anchored in the basic needs of the local community, which founded a technical training school, now Mondragon University, in 1943; the industrial cooperative Ulgor in 1956, which became Fagor Electrodomesticos; the cooperative savings bank Laboral Kutxa in 1958, 
and the Lagun Aro social security system in 1959. These four branches launched dozens of cooperatives and were the seeds of what is today the MCC. Throughout the 1960s and early 1970s some of the most important cooperatives that are now international cooperative groups were founded, including Ulma (1961), Fagor Ederlan (1963), Copreci (1963), Orona (1964), Cikautxo (1971), and Maier (1975).

Inspired by the Catholic social doctrine of the priest José María Arizmendiarrieta, ideologue of the Mondragon Cooperative Experience, these cooperatives began as small democratic organizations grounded in a robust model of collective self-governance with deep roots in the territory and a powerful sense of community. Most were created by small groups of founding members, based on values such as solidarity, hope and sacrifice, and on the notion that all of the workers were partners, financiers and co-owners of the company (Molina 2012). For example, Fagor Electrodomesticos was founded by five young workers and former students of Mondragon Technical College (Tkacz et al. 2015). Other cooperatives, such as Ederlan, were created by no more than 30 members imbued with these ideas of social transformation (Fagor Ederlan 2013).

The transition from the first organizational stage (conquest) to the second stage (economic consolidation) of the cooperative life cycle was relatively brief for most of Mondragon's international cooperative groups. Significant organizational structuring and complexity were quickly achieved. Electrodomesticos was created in 1956 and its bylaws were developed in 1959 by Arizmendiarrieta and the founding directors (Ormaechea 2003), leading to the creation of its basic governance structures: the General Assembly, the Governing Council, the Social Council, and the Management Council. This cooperative also devised some of the basic organizational and financial policies that characterize Mondragon, including the absence of stockholders, distribution of profits among members, a reserve fund, the limitation of wage differentials, and an open-door policy. Although Mondragon's basic principles were not formally approved until 1987, this set of ideas and practices were highly influential and were widely adopted by the cooperatives that followed (Whyte and Whyte 1991). The creation of the second-level cooperative organization ULARCO by Fagor Electrodomesticos, Fagor Arrasate, Copreci and Fagor Ederlan in 1965 was an important first attempt to coordinate the activities and resources of individual cooperatives and create mechanisms of inter-cooperative solidarity (Barandiaran and Lezaun 2017).

The Mondragon cooperatives rapidly achieved notable economic consolidation, especially because in those years the Spanish domestic market absorbed all the production that the cooperatives offered (Cancelo 1999). This was initially favored by the protectionist policies of Spain's autarchic economy under Franco's dictatorship, which isolated the domestic market from foreign competition, and then by the unprecedented expansion of the Spanish economy during the 1960s and early 1970s. These circumstances prompted the cooperatives' early and steady expansion. The number of workers at Mondragon cooperatives increased by about 1,000 per year between 1965 and 1975 (Bradley and Gelb 1987): Ederlan's workforce increased from 275 to 683 between 1965 and 1969 (Altuna 2006a). Other cooperatives experienced similar growth; for example, the industrial cooperative Copreci expanded from 16 jobs when it was founded in 1963 to nearly 700 by 1969 (Taylor 1994). The case of Fagor Electrodomesticos is particularly impressive: by 1969, its factories employed 2,559 workers (Altuna 2006b), more than 30 per cent of the total workforce of the 44 Mondragon cooperatives in existence at the time. It is clear that the Mondragon cooperatives far exceeded their founders' expectations in terms of growth, employment, and economic success. A founding member of Ederlan recalled:

We would never have thought that the cooperative would develop as it has and become as big as it is today. We, the founding members, never would have believed 
that. We were thinking of a cooperative of 200 or 300 people [... ] taking into account [the size of] other companies in the area. We thought we could be a little bigger or smaller than [the cooperatives] that were then in Aretxabaleta or Eskoriatza. (Fagor Ederlan, 2013, 02:32)

However, between the late 1970s and early 1980s a severe crisis hit the Spanish economy. Mondragon's cooperatives were not untouched, and some suffered financial losses and discontinued some of their activities, although most exhibited notable resilience due to several factors. First, the marked international orientation of some helped them to offset the sharp drop in domestic demand. While in 1970 exports by Mondragon's industrial division slightly exceeded 11 per cent of total sales (Cancelo 1999), by 1980 cooperatives such as Electrodomesticos, Copreci, Fagor Ederlan, and Ulma were exporting about 70 per cent of their production through commercial networks via agents and distributors in Europe and Latin America. Furthermore, Mondragon's cooperatives devised new organizational and financial policies to weather the economic crisis, including the creation of an unemployment insurance system, the relocation of workers to other cooperatives, the creation of the Intercooperative Solidarity Fund, and changes to internal profit distribution to increase the collective reserve (Bradley and Gelb 1987, Tkacz et al. 2015).

The rapid growth of various Mondragon cooperatives' size and organizational complexity led to the emergence of early tensions between their social and business perspectives, as the cooperatives combined management authority and Tayloristic methods of work organization on the assembly lines with the development and reinforcement of important social practices including pay equity, decision making on a one-person, one-vote basis, and representation of worker-members' concerns through a system of social councils (Whyte and Whyte 1991, Taylor 1994). The largest Mondragon cooperatives had entered the third organizational stage of the life cycle, coexistence, evidencing some initial symptoms of degeneration. Already a technostructure had been created by pioneering directors, sustained by charismatic links with early worker-partners (Molina 2012), who emphasized the need to put decision-making power in the hands of those with greater expertise and specialized skills. Other members advocated broad-based participation in policymaking and on the shop-floor beyond the existing representative democracy. Workers participated in the General Assembly and elected members to the governing and social councils, but there was a general feeling that they were being excluded from important decision-making and the daily organization and management of work. There was widespread discontent on the assembly lines due to the high workload stemming from authoritarian management and growing pressure for greater productivity (Taylor 1994).

A lively discussion emerged during the late 1970s and the 1980s about how decision-making processes that were efficient and at the same time congruent with democratic principles could be devised, which led some cooperatives to rethink the role of their rank-and-file workers in their organizations' day-to-day management. The Social Council governing body was reinvented, and programs redesigning the organization of work were introduced with the aim of promoting shopfloor workers' participation in decision-making (Whyte and Whyte 1991), which can be seen as early efforts to revitalize workplace democracy. Copreci was one of the pioneering companies that experimented with new forms of work organization and sociotechnical design. Between 1972 and 1984, its assembly lines were reorganized from a function base to a product base, and management committees and semi-autonomous work groups were introduced (Taylor 1994). Similar changes were subsequently adopted by other cooperatives, and by 1983 about 80 semi-autonomous 
work groups were actively operating in Mondragon's largest cooperatives (Whyte and Whyte 1991).

\section{2 | Degenerative pressures in a 'grow-or-die' dichotomy (1990 onwards)}

The initial degenerative pressures that Mondragon cooperatives faced in the early years have intensified extraordinarily since the late 1980s with increased market competition deriving from the global restructuring of the economy. Many Mondragon cooperatives have been compelled to adapt their technological and productive processes to the new competitive requirements, enhance their management knowledge and skills, and expand in Spain and abroad to maintain their competitive edge and protect cooperative employment and operations in the Basque Country:

At that time it was increasingly evident that the company was not big enough to be competitive. Our direct competitors were multinationals [...]. There were moments of tension because we were working at full capacity and were barely able to meet existing orders [...], but at the same time we were fully aware that it was necessary to acquire a global dimension not only to be competitive abroad but also to continue growing here and secure our jobs. (Interview, Maier manager)

Our fieldwork identified various constitutional, organizational, and cultural degenerative tendencies. Mondragon's cooperatives have experienced degenerative tendencies at the constitutional level based on the annexation of capitalist forms of organization and restrictions to membership rights. Between the 1960s and 1980s they acquired Basque firms, whose workers were absorbed as cooperative members. However, in the early 1990's these cooperatives started to acquire large companies, first in the domestic market and then abroad, maintaining them as capitalist subsidiaries. ${ }^{2}$ This expansion strategy has provided the Mondragon cooperatives with extraordinary economic results and job creation rates. For example, Fagor Ederlan Group's workforce increased from 1,300 to 3,600 workers between 1999 and 2015, and Maier Group's workforce rose from about 800 in 1999 to 2,700 in 2015. However, the contradiction lies in the fact that workers in the capitalist subsidiaries do not enjoy the same rights as cooperative members of the parent companies: they do not share in the ownership, distribution of profits, and management of their enterprises. Most Mondragon's international cooperative groups have more salaried employees than cooperative members on their books. In 2007, as at Maier and Electrodomesticos, only 36\% of the Ederlan Group were worker-members; overall, the proportion of non-worker-members in the Mondragon group as a whole rose from 14\% in 1991 to $70.5 \%$ in 2007 (Heras and Basterretxea 2016).

There are also clear symptoms of degeneration at the cultural level, reflected in members' growing lack of commitment to cooperative principles and values and the abandonment of some social targets in favor of business goals seeking profit and growth. The intensification of global competition has led many Mondragon cooperatives to professionalize their management. The creation in 1984 of Otalora, Mondragon's management and cooperative training center, already reflected the

\footnotetext{
${ }^{2}$ Whereas Copreci was the first cooperative to set up a production plant abroad in 1989 (Mexico), most Mondragon cooperatives started their foreign direct investment strategy in the mid-1990s. Electrodomesticos established its first foreign subsidiary in Morocco in 1994, while Maier did so in the United Kingdom in 1999, and Ederlan in Brazil in 2001.
} 
largest Mondragon cooperatives' growing need for managerial expertise in an increasingly complex and changing market environment. Since then, many Mondragon cooperatives have hired external managers who are more committed to efficiency than to the cooperative culture and social objectives:

\begin{abstract}
A great challenge in Mondragon lies in the process of acculturation to the cooperative model by new people, not only managers but also workers [...]. I myself came from the conventional business world. I knew the cooperative world because here it is very widespread. But it is not the same when you're inside: you have to get used to a culture, to values of democracy and cooperation, which are very different from those that rule out there. (Interview, middle-ranking manager, Maier)
\end{abstract}

The prevalence of a ubiquitous businesslike rhetoric that privileges the interests of competitiveness, growth, and customer/client orientation at the expense of reinforcing social discourses and the achievement of community-oriented objectives is evident (Taylor 1994). This rhetoric has facilitated a gradual distortion of cooperative values such as solidarity, participation, and education. The transformation of cooperative training and education for worker-members has played a key role. Since the 1990s, education about the philosophical, political, and practical aspects of the cooperative movement has been secondary to the benefits of technical training and basic formal training about Mondragon's basic cooperative principles (Cheney 2002). Several of the rank-andfile workers interviewed had distanced themselves from these latter and the corporate policies of self-management and participation in management, stressing that job security was the element that they valued most in their organizations (see also Heras 2014). This is clearly exemplified by a Maier worker who was asked about the reasons behind his recent incorporation as a cooperative member:

I think job security is the most important point. In a recession context, the cooperative has kept going. There have been some improvements to our working conditions, and we feel that our jobs are non-negotiable. (Interview, Maier worker)

Various factors have also triggered organizational dynamics of degeneration, grounded in the reshaping of the nature and scope of worker participation in Mondragon cooperatives. First, the greater organizational size of cooperatives and the complexity of strategic decisions that must be taken have been key factors affecting participation. Several members recognized a certain ritualization of the General Assembly and other democratic spaces, remarking that they had become symbolic spaces rather than structures where people really participated:

It's obvious that the bigger you are, the harder it is to encourage people's active participation [...]. It becomes more difficult for people to perceive a direct and tangible relationship between their participation and the impact of such participation on the organization. (Interview, Ederlan worker-member)

The transformations in the organization of work that began in the 1970s evolved significantly throughout the late 1980s and the 1990s, with the complete reconfiguration of activities and processes towards customer orientation and the introduction of prevailing models of total quality management (TQM) and lean manufacturing (Cheney 2002). One critical aspect of this involved various industrial cooperatives' implementation of the 'mini-company' system in the early 2000 s. 
This system restructures the organization so that each of its units runs as a small firm in which semi-autonomous groups of workers take decisions and resolve problems related to their area of work. The introduction of these management programs was not exempt from tensions in the cooperatives deriving from the greater workload and stress in the workshops (see Kasmir 1996 for detailed accounts of working lives in the cooperatives during these years). These models inculcated a weak self-management culture that promotes forms of manager-controlled participation assessed in terms of employees' motivation and commitment to managerial objectives (see also Cheney 2002, Heras 2014). Indeed, workers generally emphasized their perception of a clear division between management and rank-and-file members, stressing a certain discontent about their involvement in decision making.

No cooperative has entered the fourth stage of the life cycle, administrative power, characterized by the technostructure's absolute organizational control. This is evident even in the case of Electrodomesticos, which preserved the essence of its cooperative nature until its demise in November 2013, at least to the extent that the major decisions were formally taken by the cooperative governance bodies in accordance with internal procedures of representative democracy (Errasti et al. 2016). It is evident that the cooperative's bankruptcy was due to market conditions. Electrodomesticos, a weak and small company in comparison to its competitors and with a large part of its production activity located in high-cost countries, pursued a breakneck, risky strategy of growth that reached its peak with the takeover of the French giant Brandt for $€ 165$ million in 2005. The company finally collapsed with the severe economic downturn of 2008, which particularly hit the construction industry and in turn the electric appliance market, after steadily accumulating debt and a drastic fall in sales during the previous decade (Errasti et al. 2017). Fagor Electrodomesticos also had a range of serious governance problems. Important factors included the deficient flow of information between management and worker-members; the complex strategic issues that the cooperative faced in an increasingly international and competitive environment, which clearly surpassed worker-members' strategic and business skills; the lack of effective leadership; and increasing apathy and indifference among worker members who left the decision-making power in the hands of management. This was the view of an Electrodomesticos worker:

There was a distancing and even a break between the governing bodies, which increasingly had more weight, and the rank-and-file members. This circumstance worsened with the purchase of the Brandt and Wrozamet companies, since decisions no longer depended on us. We lost control and the responsibility was diluted. (Naiz, 2013, press article)

What the case of Fagor tells us about the cooperative life cycle is that intrinsic elements of the Mondragon cooperative model, including worker ownership, job stability, solidarity, democracy, and inter-cooperation, contributed to Electrodomesticos surviving longer than other companies in the same sector. Managers and worker-members echoed that if Fagor had not been a cooperative it would have fallen much earlier, and the consequences for employment in the valley would have been significantly more dramatic. The nearly 1,900 cooperative members of the Fagor parent company were offered early retirement or relocation to other cooperatives of the group:

The [Mondragon] group's solidarity and inter-cooperation instruments have been fundamental in protecting jobs. I would highlight the efforts made through Lagun Aro, such as the relocation of staff to other cooperatives, jointly-funded early 
retirement, etc. At the same time, various initiatives were put in place to boost people's employability by raising their qualifications. (Interview, MCC manager)

\title{
4.3 | Design and development of regeneration initiatives (2005 onwards)
}

After decades of tremendous growth that privileged managerial prerogatives and market orientation, between 2000 and 2002 various large Mondragon cooperatives, such as Fagor Ederlan, Maier and Copreci, initiated ideological reflections about the core practices and values of the cooperative model. For example, an Ederlan member explained this reflection in the following terms:

\begin{abstract}
We came from an intense process of growth that culminated with the opening of a production plant in Brazil (...). The members of the governing bodies perceived that it was time to look back. We started a process of ideological reflection, which other cooperatives in the group also started at the same time (...). The aim was to analyze key aspects of our experience, such as participation and social transformation, and reflect on what we could do to introduce our [cooperativist] management model into the group's [non-cooperative] associated companies. (Interview, Ederlan Governing Council member)
\end{abstract}

These internal reflections that arose almost simultaneously in several of Mondragón's most important cooperatives quickly translated to a broader debate. In 2003 the Mondragon Cooperative Congress - made up of representatives from all the group's cooperatives - recognized a general decline in democratic control and the need to revitalize essential aspects of the Mondragon experience such as participation, inter-cooperation, cooperative training and education, and the role of cooperatives in promoting positive social change (Azkarraga et al. 2012). This Congress approved what was called the 'social expansion strategy', based on the extension of cooperative values to the capitalist subsidiaries via the development of worker participation mechanisms similar to those of the Basque cooperatives. Some of the crucial agreements reached about the subsidiaries were to encourage greater transparency in decision making, implement the same participative management model as that applied in the cooperatives, aim for at least 30 per cent of worker ownership, and devote 1-5 per cent of profits to local development in the territories where the subsidiaries are located (Flecha and Ngai 2014).

These issues are clearly highlighted in the MCC Corporate Management Model currently in force, which emphasizes three aspects of promoting democratic governance and participation in the cooperatives: self-management, communication, and corporate development (Mondragon 2013). The first two of these, self-management and communication, encompass both the cooperatives and their subsidiaries, whilst the third, corporate development, is fundamentally designed for the subsidiaries. Where the self-management of cooperatives and subsidiaries is concerned, the Corporation stresses the design of horizontal organizational structures to facilitate participation and teamwork and to enable the collective definition of aims and responsibilities. 'Communication' focuses on establishing transparency policies to stimulate interpersonal relations and the flow of information within the organization, and 'corporate development' concentrates on exporting the cooperative model to capitalist firms. 
MCC's corporate policies on regeneration have subsequently promoted the implementation of concrete initiatives by many cooperatives, including those of a smaller size that operate on a local scale. However, at least in the largest international cooperative groups, regeneration does not tend to follow a detailed, transversal plan that covers all the dynamics and structures of the organizations; rather, these regeneration processes overlap and intertwine simultaneously with degenerative tendencies in the cooperatives.

At the constitutional level, some cooperatives have conducted regeneration projects aiming to transform their domestic subsidiaries into cooperatives. For example, the Basque subsidiaries Fit Automoción and Victorio Luzuriaga Usurbil were integrated as production plants of Fagor Ederlan, their workers becoming cooperative members of the parent company. In 2008 the domestic subsidiary Victorio Luzuriaga Tafalla was converted to a mixed cooperative, and most of its workers became cooperative members of the new cooperative subsidiary (for a detailed analysis, see Bretos and Errasti 2017). Maier conducted the same process in 2012 with its domestic subsidiary Maier Ferroplast. Similarly, the household appliance components manufacturer Copreci set up a mixed cooperative subsidiary in 2010 in Altsasu, Navarre. However, various domestic subsidiaries of Ederlan, Maier and other MCC's cooperatives still remain capitalist firms.

What is more, no Mondragon foreign subsidiary has been converted to a cooperative or comprehensively introduced the range of management and employment practices associated with the cooperative model. The reasons preventing the cooperativization of foreign plants are complex and varied (for a detailed analysis, see Flecha and Ngai 2014, Bretos et al. 2018, Bretos et al. 2019). Our informants often emphasized the fact that in the destination country either no cooperative legislation has been developed, or the legislation in place bears no similarity to that of the Basque Country. Likewise, they also echoed the lack of a strongly rooted cooperative culture in many foreign regions in which Mondragon cooperatives operate. For instance, a manager referred to these institutional barriers in the following terms:

[The conversion of foreign plants into cooperatives] is very complex. In many countries where we are located there is no cooperative legislation, or it is very different from the legislation that exists here [...]. Nor are there the same cultural specificities around the cooperative model and labor cooperation that exist in the Basque Country. (Interview, Ederlan manager)

Many informants also suggested that if foreign plants become cooperatives, their workers might take the decision to detach from the parent cooperative. In consequence, worker-members and managers deem the cooperativization of foreign plants as risky for the viability of the parent coop business project and the jobs of the Basque worker-members, thereby generating a dilemma for the ultimate objective of internationalization in Mondragon: keeping cooperative jobs at the Basque plants.

At the cultural level, meanwhile, some projects have been introduced to renovate and institutionalize cooperative training and education in Mondragon cooperatives. These projects, which are primarily designed and implemented by Otalora, focus on both business issues and the cooperative culture and social skills such as leadership and teamwork; however, they are primarily targeted at managers and members of the governing bodies. Some of our interviewees suggested that there was a deficit in cooperative training and education for grass-roots worker-members (see also Heras 2014). For example, an in-house survey in 2010 at an Ederlan domestic plant revealed that only 7 per cent of members knew exactly what the Mondragon cooperative principles comprise: 
I would not say that the [cooperative] training has been enough. In very little time, very complex aspects are addressed and in a very abstract way [...]. It takes time to assimilate issues such as the meaning of cooperative values. (Interview, new Maier worker-member)

At the organizational level, regeneration efforts and their results have also been mixed. Some particularly dynamic and innovative cooperatives are experimenting internally with new forms of participation. This is the case for Fagor Arrasate, which has fostered more participatory dynamics by opening up spaces for deliberation and more active participation from shop-floor workers. In this cooperative the advisor's role has been redefined to not only inform but also energize participation in the mini-councils which in turn have been reshaped to encourage the advisory role of the Social Council. Similarly, Ederlan has reconfigured the role of the mini-councils to strengthen information-sharing and has created new channels to broaden workers' involvement. For instance, participation in the discussion and elaboration of strategic plans has been expanded to include members from all strata and hierarchical levels of the cooperative. However, in cooperatives such as Ederlan and Maier there are still clear deficits regarding the participation of workers at the shop-floor level (see Altuna and Urteaga 2014 for a detailed analysis of the internal tensions at Ederlan in the 1990s and 2000s regarding participation in the management of work). The aforementioned in-house survey conducted at Ederlan revealed that 23 per cent of the workers gave a score of 1 out of 10 for their participation in the company:

The mini-company model has been showing certain signs of social exhaustion for some time (...). We must begin to rethink how to move towards models where selfmanagement is understood in a more transversal and profound way. (Interview, Ederlan manager)

Our research also found that regeneration in Mondragon has been strongly subordinated to the changing market conditions and the associated requirements imposed on the cooperatives. The political discourses of the late 1970s and early 1980s that focused on building more horizontal structures and reinforcing self-management were rapidly abandoned in light of the new competitive and growth requirements imposed by the growing globalization of markets in the late 1980s and early 1990s (Taylor 1994, Kasmir 1996). Similarly, the regeneration discourse of the early 2000s lost momentum with the arrival of the economic crisis in 2008, which forced the cooperatives to focus on economic viability and survival:

The impact of the crisis was unexpected and harsh (...). This forced us to leave many things aside. The internal discussions shifted to focus on how to safeguard employment and keep the company afloat and competitive. Our positioning was to continue growing and investing in RandD, which today has proven a successful strategy. (Interview, Maier manager)

It seems that the regenerative discourse has changed substantially since the economic crisis. The markedly political content of the regeneration plans and discourses of the early 2000s has given way to a businesslike rhetoric focused on what is called 'vivencia de los valores cooperativos' (the lived experience of cooperative values), based on strengthening cooperative values such as coresponsibility and commitment to enhancing cooperatives' economic viability (Mondragon 2016). This shift is particularly evident where the transformation of capitalist subsidiaries is concerned: 
Our organizational model is clear: here in the Basque Country we are cooperatives, but not elsewhere [...]. Introducing the cooperative model abroad is no longer on the agenda. A few years ago, this was a concern in many cooperatives, but it is no longer a matter of interest. It arose from the ideological character of the past, but did not translate into deeds anyway. [The cooperativization of foreign subsidiaries] was rather part of a discourse of belligerence and orthodoxy. This would lead nowhere nowadays [...]. What we emphasize at the subsidiaries is the lived experience of cooperative values and how to translate them into daily practice. Values such as responsibility, effort, teamwork, and workers' loyalty to the company are fundamental in all our subsidiaries. (Interview, MCC corporate manager)

\section{5 | DISCUSSION}

This article was motivated by recent calls to empirically document the evolution of cooperatives and member-based organizations (Diefenbach 2018) and shed light on the structural, organizational, and cultural dynamics that cause them to degenerate and regenerate (Jaumier 2017, Narvaiza et al. 2017). Drawing on a longitudinal analysis, we illustrate how the evolution of Mondragon's industrial cooperatives in a capitalist setting creates an intricate picture that contradicts the highly deterministic and simplistic degeneration thesis. These cooperatives have thrived for decades in highly globalized and competitive markets while maintaining, at the very least, the essence of their democratic methods and governance structures in the Basque Country, as well as their contribution to job creation, economic development, and social cohesion in the local area.

Our research reveals how cooperatives confronted with a 'grow-or-die' dichotomy in global capitalist markets have to cope with unique constitutional, cultural, and organizational degenerative pressures which are substantially different from those faced by small cooperatives operating exclusively in the domestic market. As the literature contends, small organizational size and positioning in niche markets with little competition from larger capitalist firms are critical conditions if cooperatives are to maintain their community-oriented purposes and democratic functioning (e.g. Jaumier 2017). Articulating regeneration processes is much simpler for small local cooperatives, as it is easier for them to enact the collective appropriation of the business project, enhance mutual recognition and trust, and build social links among their members ( $\mathrm{Ng}$ and $\mathrm{Ng} \mathrm{2009,} \mathrm{Narvaiza}$ et al. 2017). In contrast, regeneration in international cooperative groups is much more complex due to their large organizational dimension, the severe economic pressures imposed by competing in global markets, and the fact that they operate across institutionally and culturally distant countries, which hampers growth following the cooperative formula and essence (Bretos et al. 2019).

As we have seen, international growth can transform cooperatives into 'coopitalist' hybrids (Bretos and Errasti 2018) composed of a cooperative nucleus (parent company) and a capitalist periphery (subsidiaries) in which non-owner workers are deprived of the rights and benefits of cooperative membership. To meet global market requirements, cooperatives may be compelled to put greater power into the hands of technocratic management at the expense of workers' control and rank-and-file participation, leading to the consolidation of oligarchic trends. At Mondragon this tendency has been boosted by the introduction of dominant regimes of managerialism in the form of mainstream models of TQM and lean manufacturing (Cheney 2002), which have promoted shallow, manager-driven forms of participation that are confined to the work area and assessed in terms of productivity. Lastly, the prevalence of conventional business objectives 
can displace socially-oriented goals and reshape cooperative practices in line with managerial priorities. Participation and self-management seem to have lost some of the political content of yesteryear in favor of job stability for worker-members. Similarly, education and training policies have shifted to focus primarily on managerial skills and technical training at the expense of the philosophical, political, and practical aspects of cooperativism. To some extent these changes have been influenced by broader societal changes, including growing unemployment and precarious working conditions, and more individualistic behavior in the social, labor and civic spheres of community life (Heras 2014), and the process of 'de-ideologization [that] has affected the whole of society and, as members of that society, the cooperative social body as well' (Azkarraga et al. 2012: 78). Nevertheless, we cannot overlook the key role played by Mondragon's technocratization of management and the associated managerialist rhetoric that has distorted cooperative values, privileging concepts such as quality and customer service, efficiency, growth, and competitiveness.

At the same time, our analysis demonstrates that cooperatives are not passive actors, completely subject to isomorphic pressures that will sooner or later inevitably lead them to stagnate in a state of inaction or become capitalist organizations, as degeneration theory would suggest (Webb and Webb, 1921; Meister, 1984). They can mobilize resources and activate processes of organizational change to revitalize cooperative values and practices. These include the recovery of countervailing social discourses emphasizing democracy, social transformation, and community development; the reinforcement of broad-based participation both on the shop-floor and in strategic management; the updating and institutionalization of cooperative education and training; and the cooperativization of capitalist subsidiaries.

However, our findings do not fit well with the prevalent view of regeneration as a consistent homogeneous process that pervades all organizational spheres and takes place in a sequential fashion after degeneration, deactivating all of its consequences (e.g. Batstone 1983, Rosner 1984). According to the evidence gathered in our analysis, degeneration and regeneration are not mutually exclusive and can occur simultaneously, as the study by Vezina et al. (2017) on the life cycle of social innovation in a mature social economy enterprise also evokes. While some recent studies have acknowledged that regenerative transitions might not have immediate effects (e.g. Narvaiza et al. 2017, Cook 2018), suggesting the existence of a temporary period in which competing degenerative and regenerative forces coexist, our analysis uncovers how this conflictual situation can remain permanently unresolved. Mondragon's international cooperative groups have developed some interesting regeneration initiatives by cooperativizing some of their domestic subsidiaries, updating and institutionalizing cooperative education and training for managers and members of their governing bodies, and revitalizing certain employee voice structures to strengthen information-sharing and horizontal communication, and broaden grassroots participation in some decisions. At the same time, these cooperatives have continued growing through the acquisition of capitalist firms while cooperative education and training for rank-and-file worker-members continue to suffer from a systematic deficit, and participation in the work area continues to be shaped by dominant, managerially-controlled systems.

The permanent overlap of degenerative and regenerative tendencies is sustained, at least partially, by the fact that regeneration does not appear to be a consistent process but is rather contingent on changing market conditions and the associated requirements imposed on cooperatives. Discussions at Mondragon in the 1980s about reorganizing work to foster substantial self-management were pushed into the background in the early 1990s due to the escalation of globalization pressures, leading the cooperatives to begin a new period of international growth and to introduce new models of work organization oriented towards customer satisfaction. Similarly, 
the new regeneration schemes developed since the early 2000s have been significantly subordinated to the impact of the global economic crisis and consequent strategies for economic survival and business competitiveness. What is more, it seems that in recent years MCC's technostructure has invested significant effort in remodeling the regenerative discourse, emptying it of its political content and adapting it to managerial prerogatives; therefore it will be important to follow how regeneration discourse and practices evolve over the next few years.

This picture appears consistent with the paradoxical perspective proposed by some authors to explain the concomitant existence of degenerative and regenerative tendencies (e.g. Hernandez 2006, Storey et al. 2014). In this view, tensions and internal contradictions are understood as a natural state of affairs, since cooperatives 'are neither fully democratic nor oligarchic but sites of continuous and unresolved contestation between oligarchic and democratic tensions' (Storey et al. 2014: 641). While we concur, it is equally evident that this perspective neglects political questions about regeneration in cooperatives. Why have Mondragon cooperatives cooperativized some of their domestic subsidiaries while others have remained capitalistic in form and essence, both at home and abroad? A partial response lies in the institutional and cultural differences between the Basque Country and other national divides, which may translate into perennial and unresolvable tensions for Mondragon, since, following the paradox approach, cooperatives permanently have to cope with 'internal contradictions that do not necessarily lead to resolution, but rather, are everlasting' (Hernandez 2006: 108). However, we also need to consider the fact that this global labor hierarchy is essential for Mondragon worker-members to safeguard their interests and maintain their decision-making power (Bretos et al. 2019). As Kasmir (2016: 55) succinctly points out, job security, decent pay, and workplace democracy in the Basque Country rest upon poorly paid and insecure wage labor elsewhere'. This suggests that cooperatives might regenerate only certain aspects of cooperative organizational life while maintaining other degenerative tendencies intentionally unaltered so that they can continue exploiting the resources and possibilities offered by a capitalist market economy.

In light of these critical questions, future studies might explore the links between regenerative strategies and political questions. In broader terms, combining a paradox approach with poweraware and politically-informed approaches could be useful to further understand how cooperatives manage tensions and internal contradictions at each organizational stage of the life cycle, and which organizational actors benefit, and how, from reversing some degenerative tendencies while maintaining others intact.

\section{O R C I D}

Ignacio Bretos (D) https://orcid.org/0000-0002-4941-2028

\section{REFERENCES}

Altuna C., 2006a, Fagor Ederlan. Eusko Ikaskuntza - Sociedad de Estudios Vascos. Retrieved from http:// aunamendi.eusko-ikaskuntza.eus/eu/fagor-ederlan/ar-52049/.

Altuna C., 2006b, Fagor Electrodomésticos. Eusko Ikaskuntza - Sociedad de Estudios Vascos. Retrieved from http: //aunamendi.eusko-ikaskuntza.eus/eu/fagor-electrodomesticos/ar-52128/.

Altuna R. and Urteaga E., 2014, 'La cooperativa Fagor Ederlan: El “lean manufacturing” como modelo de gestión', CIRIEC-España, Revista de Economía Pública, Social y Cooperativa, 82, 29-64.

Azkarraga J., Cheney G. and Udaondo A., 2012, 'Workers participation in a globalized market: Reflections on and from Mondragon', in M. Atzeni (ed.), Alternative Work Organisations, New York: Palgrave Macmillan.

Barandiaran X. and Lezaun J., 2017, 'The Mondragon experience', In J. Michie, J. R. Blasi, and C. Borzaga (eds.), The Oxford Handbook of Mutual, Co-Operative, and Co-Owned Business, New York: Oxford University Press. 
Batstone E., 1983, 'Organization and orientation: A life cycle model of French cooperatives', Economic and Industrial Democracy, 4, 139-161.

Ben-Ner A., 1984, 'On the stability of the cooperative type of organization', Journal of Comparative Economics, 8 , 247-260.

Bradley K. and Gelb A., 1987, 'Cooperative labor relations: Mondragon's response to recession', British Journal of Industrial Relations, 25, 77-99.

Bretos I., Díaz-Foncea M. and Marcuello C., 2018a, 'Cooperativas e internacionalización: Un análisis de las 300 mayores cooperativas del mundo', CIRIEC-España, Revista de Economía Pública, Social y Cooperativa, 92, 5-37.

Bretos I. and Errasti A., 2016, 'Dinámicas de regeneración en las cooperativas multinacionales de Mondragón: La reproducción del modelo cooperativo en las filiales capitalistas', CIRIEC-España, Revista de Economía Pública, Social y Cooperativa, 86, 5-34.

Bretos I. and Errasti A., 2017, 'Challenges and opportunities for the regeneration of multinational worker cooperatives: Lessons from the Mondragon corporation - a case study of the Fagor Ederlan Group', Organization, 24, $154-173$.

Bretos I. and Errasti A., 2018, 'The challenges of managing across borders in worker cooperatives: Insights from the Mondragon cooperative group', Journal of Co-operative Organization and Management, 6, 34-42.

Bretos I., Errasti A. and Marcuello C., 2018b, 'Ownership, governance, and the diffusion of HRM practices in multinational worker cooperatives: Case study evidence from the Mondragon Group', Human Resource Management Journal, 28, 76-91.

Bretos I., Errasti A. and Marcuello C., 2019, 'Multinational expansion of worker cooperatives and their employment practices: Markets, institutions, and politics in Mondragon', ILR Review, 72, 580-605.

Bretos I. and Marcuello C., 2017, 'Revisiting globalization challenges and opportunities in the development of cooperatives', Annals of Public and Cooperative Economics, 88, 47-73.

Bretos I. and Morandeira J., 2016, 'La Economía Social ante la actual Crisis Económica en la Comunidad Autónoma del País Vasco', REVESCO, Revista de Estudios Cooperativos, 122, 7-33.

Cancelo A., 1999, 'Mondragón Corporación Cooperativa: Historia de una experiencia', Revista Internacional de Estudios Vascos, 44, 323-357.

Cathcart A., 2013, 'Directing democracy: Competing interests and contested terrain in the John Lewis Partnership', Journal of Industrial Relations, 55, 601-620.

Cathcart A., 2014, 'Paradoxes of participation: Non-union workplace partnership in John Lewis', International Journal of Human Resource Management, 25, 762-780.

Chaves R. and Sajardo A., 2004, 'Social economy managers: Between values and entrenchment', Annals of Public and Cooperative Economics, 75, 139-161.

Cheney G., 2002, Values at Work: Employee Participation Meets Market Pressure at Mondragon, Ithaca, NY: Cornell University Press.

Cook M. L., 2018, 'A life cycle explanation of cooperative longevity', Sustainability, 10, 1-20.

Cornforth C., 1995, 'Patterns of cooperative management: Beyond the degeneration thesis', Economic and Industrial Democracy, 16, 487-523.

Cornforth C., Thomas A., Lewis R. and Spear R., 1988, Developing Successful Working Co-operatives, London: Sage.

Denis J.-L., Lamothe L. and Langley A., 2001, 'The dynamics of collective leadership and strategic change in pluralistic organizations', Academy of Management Journal, 44, 809-837.

Dimaggio P. J., and Powell W. W., 1983, 'The iron cage revisited: Institutional isomorphism and collective rationality in organizational fields', American Sociological Review, 48, 147-160.

Diamantopoulos M., 2012, 'Breaking out of co-operation's 'iron cage': From movement degeneration to building a developmental movement', Annals of Public and Co-operative Economics, 83, 199-214.

Diefenbach T., 2018, 'Why Michels' "iron law of oligarchy" is not an iron law - and how democratic organisations can stay "oligarchy-free”, Organization Studies, in press, https://doi.org/10.1177/0170840617751007.

Eikenberry A., 2009, 'Refusing the market: A democratic discourse for voluntary and nonprofit organizations', Nonprofit and Voluntary Sector Quarterly, 38, 582-596.

Errasti A., Bretos I. and Etxezarreta E., 2016, 'What do Mondragon Coopitalist multinationals look like? The rise and fall of Fagor Electrodomésticos S. Coop. and its European subsidiaries', Annals of Public and Cooperative Economics, 87, 433-456. 
Errasti A., Bretos I. and Nunez A., 2017, 'The Viability of Cooperatives: The Fall of the Mondragon Cooperative Fagor', Review of Radical Political Economics, 49, 181-197.

Fagor Ederlan, 2013, Testigantzak/Testimonios [video file]. Retrieved from http://fagorederlan50.com/es/ testimonios/.

Flecha R. and Ngai P., 2014, 'The challenge for Mondragon: Searching for the cooperative values in times of internationalization', Organization, 21, 666-682.

Giagnocavo C., Gerez S. and Campos Climent V., 2014, 'Paths to cooperative survival: structure, strategy and regeneration of fruit and vegetables cooperatives in Almeria and Valencia, Spain', Annals of Public and Cooperative Economics, 85, 617-639.

Greenwood R., Oliver C., Sahlin K. and Suddaby R., 2008, Sage Handbook of Organizational Institutionalism, London: Sage.

Heras I., 2014, 'The ties that bind? Exploring the basic principles of worker-owned organizations in practice', Organization, 21, 645-665.

Heras I. and Basterretxea I., 2016, 'Do co-ops speak the managerial lingua franca? An analysis of the managerial discourse of Mondragon cooperatives', Journal of Co-operative Organization and Management, 4, 13-21.

Hernandez S., 2006, 'Striving for control: Democracy and oligarchy at a Mexican cooperative', Economic and Industrial Democracy, 27, 105-135.

Hunt G. C., 1992, 'Division of labour, life cycle and democracy in worker co-operatives', Economic and Industrial Democracy, 13, 9-43.

Jaumier S., 2017, 'Preventing chiefs from being chiefs: An ethnography of a co-operative sheet-metal factory', Organization, 24, 218-239.

Kasmir S., 1996, The Myth of Mondragon: Cooperatives, Politics, and Working-Class Life in a Basque Town, Albany: State University of New York Press.

Kasmir S., 2016, 'The Mondragon cooperatives and global capitalism: A critical analysis', New Labor Forum, 25, 52-59.

Karra N., Tracey P. and Phillips N., 2006, 'Altruism and agency in the family firm: Exploring the role of family, kinship, and ethnicity', Entrepreneurship Theory and Practice, 30, 861-877.

Langley A., 1999, 'Strategies for theorizing from process data', Academy of Management Review, 24, 691-710.

Langley A., Smallman C., Tsoukas H. and Van de Ven A. H., 2013, 'Process studies of change in organization and management: Unveiling temporality, activity, and flow', Academy of Management Journal, 56, 1-13.

Langmead K., 2016, 'Challenging the degeneration thesis: The role of democracy in worker cooperatives?' Journal of Entrepreneurial and Organizational Diversity, 5, 79-98.

Leach D. K., 2005, 'The iron law of what again? Conceptualizing oligarchy across organizational forms', Sociological Theory, 23, 312-337.

Leonard-Barton D., 1990, 'A dual methodology for case studies: synergistic use of a longitudinal single site with replicated multi sites', Organization Science, 1, 248-266.

Martin E. J., 2015, 'Oligarchy, anarchy, and social justice', Contemporary Justice Review, 18, 55-67.

Michels R., 1915, Political parties: A sociological study of the oligarchical tendencies of modern democracy, New York: Hearst's International Library.

Miyazaki H., 1984, 'On success and dissolution of the labour-managed firm in the capitalist economy', Journal of Political Economy, 92, 909-931.

Meister A., 1984, Participation, Associations, Development, and Change, New Brunswick: Transaction Books.

Meyer J. W. and Rowan B. 1977, 'Institutionalized organizations: Formal structure as myth and ceremony', American Journal of Sociology, 83, 340-363.

Molina F., 2012, 'Fagor Electodomésticos: The multinationalisation of a Basque co-operative, 1955-2010', Business History, 54, 945-963.

Molina F. and Miguez A., 2008, 'The origins of Mondragon: Catholic co-operativism and social movement in a Basque valley (1941-59)', Social History, 33, 284-298.

MONDRAGON, 2013, Corporate management model, Arrasate-Mondragón: MCC.

MONDRAGON, 2016, Política Socioempresarial 2017-2020. Internal document, MCC.

MONDRAGON, 2017, 2016 Annual Report, Arrasate-Mondragón: MCC. 
Narvaiza L., Aragon-Amonarriz C., Iturrioz-Landart C., Bayle-Cordier J. and Stervinou S., 2017, 'Cooperative Dynamics during the Financial Crisis: Evidence from Basque and Breton Case Studies', Nonprofit and Voluntary Sector Quarterly, 46, 505-524.

NAIZ 2013, 'Cuanto más grandes nos hemos hecho, hemos perdido el ideario cooperativista', retrieved from www.naiz.eus/eu/actualidad/noticia/20131103/cuanto-mas-grandes-nos-hemos-hecho-hemos-perdido-elideario-cooperativista.

$\mathrm{Ng} \mathrm{C.} \mathrm{W.} \mathrm{and} \mathrm{Ng} \mathrm{E.,} \mathrm{2009,} \mathrm{'Balancing} \mathrm{the} \mathrm{democracy} \mathrm{dilemmas:} \mathrm{Experiences} \mathrm{of} \mathrm{three} \mathrm{women} \mathrm{workers'} \mathrm{cooperatives}$ in Hong Kong', Economic and Industrial Democracy, 30, 182-206.

Ormaechea J. M., 2003, Didáctica de una experiencia empresarial: El cooperativismo de Mondragón, Aretxabaleta: Otalora.

Orton J. D., 1997, 'From Inductive to Iterative Grounded Theory: Zipping the Gap between Process Theory and Process Data', Scandinavian Journal of Management, 13, 419-438.

Ozcan P. and Eisenhardt K. M., 2009, 'Origin of alliance portfolios: Entrepreneurs, network strategies, and firm performance', Academy of Management Journal, 52, 246-279.

Paranque B. and Willmott H., 2014, 'Cooperatives - saviours or gravediggers of capitalism? Critical performativity and the John Lewis Partnership', Organization, 21, 604-625.

Rosner M., 1984, 'A search for “coping strategies” or forecasts of cooperative degeneration?' Economic and Industrial Democracy, 5, 391-399.

Rothschild J., 2016, 'The logic of a co-operative economy and democracy 2.0: Recovering the possibilities for autonomy, creativity, solidarity, and common purpose', Sociological Quarterly, 57, 7-35.

Russell R., 1984, 'The role of culture and ethnicity in the degeneration of democratic firms', Economic and Industrial Democracy, 5, 73-96.

Sousa J. and Herman R., 2012, A Co-operative Dilemma, Saskatoon: Centre for the Study of Co-operatives.

Storey J., Basterretxea I. and Salaman G., 2014, 'Managing and resisting 'degeneration' in employee-owned businesses: A comparative study of two large retailers in Spain and the United Kingdom', Organization, 21, 626-644.

Taylor P. L., 1994, 'The Rhetorical Construction of Efficiency: Restructuring and Industrial Democracy in Mondragon, Spain', Sociological Forum, 9, 459-489.

Tkacz M., Arando S. and Pacut A., 2015, Cooperative response to societal and market challenges - The motives and stages of development of Mondragon cooperative model. A case study', Ekonomia Społeczna, 2, 69-84.

Van de Ven A. H., 2007, Engaged Scholarship: A Guide for Organizational and Social Research, Oxford: Oxford University Press.

Varman R. and Chakrabarti M., 2004, 'Contradictions of democracy in a workers' cooperative', Organization Studies, 25, 183-208.

Vezina M., Malo M. C. and Ben Selma M., 2017, 'Mature social economy enterprise and social innovation: The case of the Desjardins Environmental Fund', Annals of Public and Cooperative Economics, 88, 257-278.

Webb S. and Webb B., 1921, The Consumers' Co-operative Movement, London: Longmans.

Whyte W. F. and Whyte K. K., 1991, Making Mondragon: The Growth and Dynamics of the Worker Cooperative Complex, Ithaca, NY: ILR Press.

Yin R. K., 1984, Case Study Research: Design and Methods, London: Sage.

How to cite this article: Bretos I, Errasti A, Marcuello C. Is there life after degeneration? The organizational life cycle of cooperatives under a 'grow-or-die' dichotomy. Ann Public Coop Econ. 2020;91:435-457. https://doi.org/10.1111/apce.12258 